THE UNIVERSITY OF CHICAGO

DEPARTMENT OF THE GEOPHYSICAL SCIENCES

CLOUD PHYSICS LABORATORY

Technical Note No. 41

\title{
ICE CRYSTAL TERMINAL VELOCITIES
}

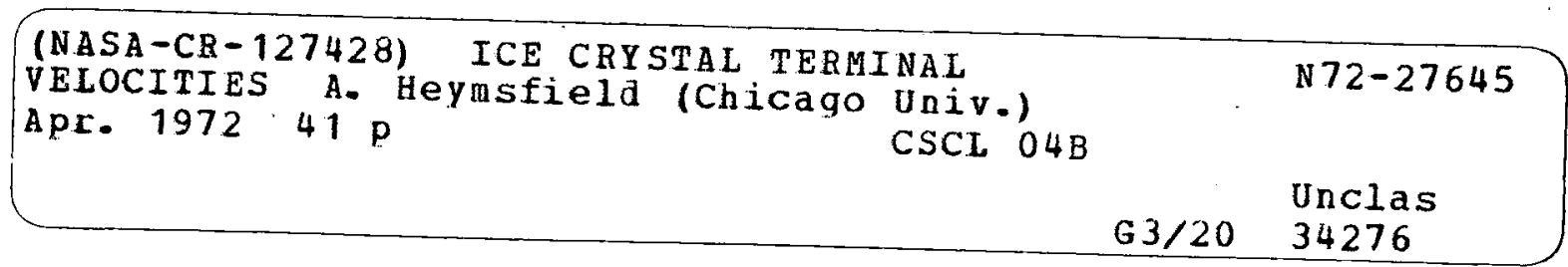

by

Andrew Heymsfield

Chicogo, Illinois

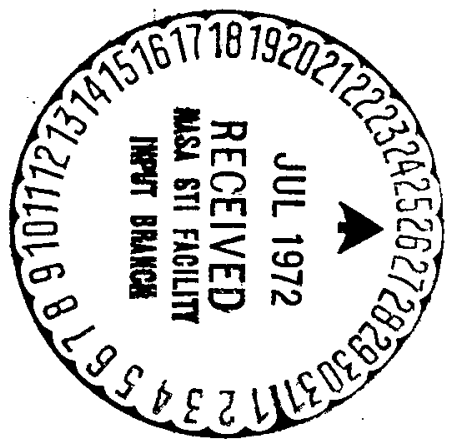

April 1972

This reseorch was sponsored by a NASA troineeship, a NASA Gront number NGR $-14-001-148$, and NSF Gronts GA 28190X, GA 20470 and GA 11088.

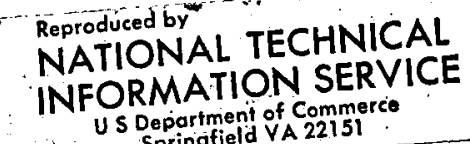




\author{
THE UNIVERSITY OF CHICAGO \\ Department of the Geophysical Sciences
}

TECHNICAL NOTE NO. 41

CLOUD PHYSICS LABORATORY

ICE CRYSTAL TERMINAL VELOCITIES

by

Andrew Heymsfield

Chicago, Illinois

April 1972

This research was sponsored by a NASA traineeship, NASA Grant NGR-14-001-148, and NSF Grants GA 28190X, GA 20470 and GA 11088 . 
TABLE OF CONTENTS

Page

LIST OF FIGURES

111

LIST OF TABLES

1v

ABSTRACT

$\mathrm{v}$

1. INTRODUCTION 1

2. BASIS OF APPROACH 4

A. Drag Coefficient 6

B. Aspect Ratio 10

C. Ice Crystal Density 11

3. TERMINAL VELOCITY CALCULATIONS 14

A. Bullet Crystals 14

B. Columns 14

C. Plates 15

D. Stellar and Dendritic Crystals 15

E. Needles 16

F. Specific Equations at $1000 \mathrm{mb}$

4. CONCLUSIONS 18

ACKNOWLEDGEMENTS 20

$\begin{array}{ll}\text { REFERENCES } & 21\end{array}$ 
1 Bullet crystal length versus width from crystals samples in cirrus clouds.

Column crystal length versus width
crystals samples in cirrus clouds.

3 Micro-photographs of particles used for density computation:

a lcing out altocumulus

b cirrostratus

c leing out altocumulus

d-e particles collected (in cirrostratus) and melted in silicone oil

f replica in nimbostratus

4

$6 a$

$6 b$

$6 c$

$6 d$

$6 e$
Bullet crystal length versus bulk density for different cloud forms. Also included is density computed from crystal mass.

Dendritic diameter versus density. for $1000 \mathrm{mb}$ and $400 \mathrm{mb}$. and $400 \mathrm{mb}$.

Plate terminal velocity versus length at $1000 \mathrm{mb}$ and $400 \mathrm{mb}$ plates with extensions, and stellar crystals. 


\section{LIST OF TABLES}

Table

Following

Page

I

Relationships between length and width for the different crystal forms studied.

II Equations for terminal velocity as a function of length for the different crystal forms studied. 16 Specific equations for terminal velocities at $1000 \mathrm{mb}$ and $400 \mathrm{mb}$, using these equations. 


\begin{abstract}
Terminal velocities of different ice crystal forms were calculated using the most recent ice crystal drag coefficients, aspect ratios, and densities. The equations derived were primarily for use in calculating precipitation rates by sampling particles with an alrcraft in cirrus clouds, and determining particle size in cirrus clouds by Doppler radar. However, the equations are sufficiently general for determining particle terminal velocity at any altitude, and most any crystal type. Two sets of equations were derived. The "general" equations provide a good estimate of terminal velocities at any altitude. The "specific" equations are a set of equations for ice crystal terminal velocities at $1000 \mathrm{mb}$. The calculations are in good agreement with terminal velocity measurements. The results from the present study were also compared to prior calculations by ohers and seem to give more reasonable results, particularly at higher altitudes.
\end{abstract}




\section{Introduction}

A knowledge of the terminal velocities of ice crystals is necessary in order to study ice crystal growth in clouds, evaporation in subcloud regions, and in the calculation of precipitation rates. Thus, the terminal velocity is a basic parameter in the modeling of any ice precipitation mechanism. It is also essential when estimating ice crystal size by measuring particle fall velocity with Doppler radar. In spite of its importance, no comprehensive study of ice crystal terminal velocities has been made. Available studies have suffered from the lack of differentiation of crystalline habit, degree of riming, and ice crystal density, from small sample sizes, and inaccuracies in the actual measurement technique.

The first published measurements of terminal velocities of natural ice crystals were made by Nakaya and Terada (1935), and Nakaya (1954). They found that the terminal velocities of plane dendrit1c, spatially dendritic, and powder snow crystal forms remained constant, independent of length. However, it has been mentioned by Bashkirova and Pershina (1964), and later by Brown (1970), that the ice crystals probably were not falling at terminal velocity between the points of measurement. In contrast, the present author found that the crystals should indeed have reached at least $99 \%$ of terminal velocity. Futhermore, some of Nakaya and Terada's other measurements of terminal velocity do not support their initial contention of a constant terminal velocity for dendritic crystals. This is evident from Plate II, Photograph 5 , 
in Nakaya and Terada and page 108 in Nakaya which show a large dendritic crystal with a terminal velocity of $49 \mathrm{~cm} \mathrm{sec}$, $^{-1}$ and in Plate II, Figure $7 a$ in Nakaya and Terada, which shows a spatial dendrite with a terminal velocity of $49 \mathrm{~cm} \mathrm{sec}-1$.

Using data by Nakaya (1954) for measuring aspect ratios and to estimate densities of ice crystals, Magono (1954) supposedly verified the terminal velocities determined by Nakaya and Terada. For needles, Magono estimated density to be $0.15 \mathrm{gm}^{-3}$, which is generally too low, and a drag coefficient corresponding to that of an infinite cylinder, which is only approximately correct. In estimating plane dendritic terminal velocities, he assumed that the thickness was independent of dimension, which is not generally found in nature. Therefore, his calculations are not generally applicable.

In the terminal velocity measurements of Bashkirova and Pershina (1964), care was taken to separate the crystal forms according to type, aspect ratios, and degree of riming. However, their sample size was quite small for each crystal type. Brown (1970) measured terminal velocities of different erystal forms and found the terminal velocities were consistently higher than those measured by Nakaya and Terada, and those computed by Magono. The most recent terminal velocity measurements are those by Yagi (1970), who measured the terminal velocities of a large sample of small ice crystals. However, the mean ice crystal size was only $0.11 \mathrm{~mm}$. 
Employing a strictly computational approach, Cornford (1965) used the limited terminal velocity data available to deduce relationships between the Reynolds number and Best number (the product of the drag coefficient and the square of the Reynolds number), from which the terminal velocity can be calculated. The equations presented for calculating terminal velocities are applicable to precipitation particles at any height in the atmosphere at which they may be sampled. Therefore, precipitation rates can be determined with aircraft measurement of particle distributions from a knowledge of terminal velocities of the precipitation forms.

In the present study, terminal velocities of ice crystals were calculated using an approach similar to that of Cornford, only using information for drag coefficients, ice crystal densities, and aspect ratios, which have only recently become avallable. 
2. Basis of approach

In this study, a technique similar to that of Cornford's was used for computing terminal velocities. Cornford started by calculating the drag coefficient, $c_{d}$, for the different particle forms over a wide range of Reynolds number, Re, since this information was not readily available. Measurements of terminal velocities of the ice crystal forms and an estimate of mass, $m$, and cross sectional area, $A$, gave $C_{d}$ and $R e$.

Thus,

$$
c_{d}=m g /\left(0 \cdot 5 \cdot p_{f} u^{2} A\right)
$$

and

$$
\operatorname{Re}=u D / \mu \text {, }
$$

where $m$ is the mass of the ice particle, $A$ is the cross sectional area which the particle presents to the flow, $e_{f}$ is the density of air, $\mu$ is the kinematic viscosity of air, $g$ is the acceleration due to gravity, $D$ is the crystal width (w) for columnar forms and diameter for platelike forms, and $u$ is the ice crystal terminal velocity. Cornford found it convenient to parameterize using the Best number, $X=C_{d} R e^{2}$, which depends only on the particle's type and position in the atmosphere. Thus,

$$
X=C_{d} R e^{2}=2 m D^{2} g / \rho_{f}^{\mu}{ }^{2} A .
$$

For each type of particle, Cornford expressed the relationship between $\mathrm{C}_{\mathrm{d}}$ and $\mathrm{Re}$, deduced from ground level measurements, as a relationship between $X$ and $R e$, and computed Re and $u$ for similar particles sampled at higher altitudes. This relationship was in the form

$$
\text { Log Re }=G+B(\log X)+C(\log X)^{2} \text {. }
$$


Thus, $\quad u=\frac{\mu}{D} \quad\left\{\operatorname{antilog}\left[G+B(\log X)+C(\log X)^{2}\right]\right\}$.

Unfortunately, the data for drag coefficient, aspect ratio and density of the particles are not sufficiently accurate to estimate terminal velocities much above those at which the terminal velocity measurements were made. For columns, Cornford used an aspect ratio of $w / L=0.33$, where $w$ is the column width and $L$ is the column length, and assumed a density of $0.3 \mathrm{gm} \mathrm{cm}^{-3}$ Compared to our recent data, this gives an aspect ratio 1.65 times too large, a density 2.15 times too small and a drag coefficient 4.43 times too small for a $1 \mathrm{~mm}$ column, at $400 \mathrm{mb}$. The resulting difference in terminal velocity is greater by $60 \%$ at $400 \mathrm{mb}$. For needles, he assumed that the density was $0.15 \mathrm{gm} \mathrm{cm}^{-3}$, independent of size. This value is about 3 times too small for a $5 \mathrm{~mm}$ needle, considering recent measurements by ono (1969). The drag coefficient of a $5 \mathrm{~mm}$ needle is 4 times greater in this study than that used by Cornford and the aspect ratio is 4 times lower. The difference in terminal velocity for a $5 \mathrm{~mm}$ needle falling at $400 \mathrm{mb}$, compared to the present approach, is greater by a factor of 2 .

To improve on Cornford's approach, more accurate values for drag coefficient, aspect ratio and density were used in calculating terminal velocities. The Best number and terminal velocity are both parameterized in terms of the crystal length (diameter). The following subsections describe the sources of these data. 


\section{a. Drag coefficient}

The most difficult of all the parameters to determine is the drag coefficient. In this study, the drag coefficients used were exclusively from tank experiments. Drag coefficients for cylinders and discs were determined experimentally by Jayaweera and Cottis (1969). They experimentally determined the Reynolds number for specific values of the Best number for cylinders and discs (plates) falling steadily in a viscous fluid in their preferred orientation. These authors mention that this covers the range of Best numbers from about 1 to $10^{4}$ (or about 1 to $10^{2}$ for the Reynolds number) for both discs and cylinders. These values are well within the limits of the present study. Experiments were performed in several different fluids for different aspect ratios of cylinders and discs. Wall effects on the drag force were taken into account. For cylinders, aspect ratios of $1.0,0.5$, and 0.1 were used for determining the Reynolds number as a function of aspect ratio. For discs, aspect ratios ranging from 0.01 to 0.8 were used. It was found that for discs, the drag coefficient was almost insensitive to the aspect ratio over the range of aspect ratios studied. However, for cylinders, the drag coefficient was dependent upon the aspect ratio. The results of this study agreed with that by Schmiedel (1928), and Willmarth, Hawk, and Harvey (1964), for discs, and Jayaweera and Mason (1965) for cylinders.

To use the drag coefficient data by Jayaweera and Cottis, a least squares polynomial equation was fit in the following form to each of the curves of Reynolds number versus Best number for the different aspect ratios: 


$$
\log \operatorname{Re}=G+B \log X+C(\log X)^{2}+H(\log X)^{3} \text {, }
$$

where

$$
\begin{aligned}
& R e=u D / \mu, \\
& X=2 m D^{2} g / \rho_{f} \mu^{2} A .
\end{aligned}
$$

and

The coefficients $G, B, C$, and $H$ for columns, plates, and bullets are presented in Table II.

It was mentioned above that Jayaweera and Cottis determined the Reynolds number for specific values of the Best number for cylinders with aspect ratios 0.5 and 0.1 , and that the drag coefficient for cylinders was dependent upon the aspect ratio. From the next section, it can be inferred that the aspect ratio for columnar and bullet crystals decreases from approximately 0.5 for small crystal lengths, to 0.18 for a $1 \mathrm{~mm}$ crystal. The Best number for a $1 \mathrm{~mm}$ bullet crystal at $400 \mathrm{mb}$ is 149 . Using the Reynolds number corresponding to an aspect ratio of 0.1 , one obtains a $20 \%$ higher terminal velocity than when using the Reynolds number corresponding to an aspect ratio of 0.5 . Therefore to obtain the best Reynolds number an interpolation was used between the curves of aspect ratio 0.5 and 0.1 . A best fit was found to be:

$$
\Delta \operatorname{Re}=(\operatorname{Re}(w / L=0 . I)-\operatorname{Re}(w / L=0.5))\left(-2.56(w / L)^{0.5}+1.81\right) .
$$

which is added to $R e_{W / L}=0.5$ to find the actual Reynolds number. It was found that delta increases the calculated terminal velocity for bullet and columns by $9 \%$ at $1000 \mathrm{mb}, 12 \%$ at $400 \mathrm{mb}$, and $15 \%$ at $200 \mathrm{mb}$, for a crystal length of $1 \mathrm{~mm}$.

To estimate the drag coefficient of dendritic crystals, the tank data determined by Podzimek (1968) was used. He found that the drag coefficient for plateforms with outgrows, stellar with narrow arms, and stellar forms with broad arms, was

$$
C_{d}=20.2 R e^{-0.466}
$$


This same drag coefficient was used to determine fall velocities of dendritic crystals.

The drag coefficient for bullet crystals, the predominant cirrus type, has also been determined from tank experiments. Podzimek determined the drag coefficient for a cylinder with aspect ratio of 0.5 with a pyramid on one end, and pyramid angle $60^{\circ}$. The drag coefficient $C_{d B}$ for this column with a pyramid at one end was

$$
\mathrm{C}_{\mathrm{dB}}=3.95 \mathrm{Re}^{-0.273}
$$

For a column form without a pyramid at one end, of aspect ratio 0.5 , Podzimek found that the drag coefficient $c_{d C}$ was

$$
C_{d C}=5.5 \operatorname{Re}^{-0.249}
$$

One can then formulate the terminal velocity for bullet crystals in terms of the terminal velocity for columnar crystals. If the ratio of the Best number for a bullet crystal to that of a column, with equal Reynolds numbers, can be found, then the Reynolds number - Best number relationships determined by Jayaweera and Cottis can be used. The ratio of the Best number for a bullet, $X_{B}$, to that of a column, $X_{C}$, of equal Reynolds number, corresponding to an aspect ratio of 0.5 , is

$$
\mathrm{X}_{\mathrm{B}} / \mathrm{X}_{\mathrm{C}}=\mathrm{C}_{\mathrm{dB}} \operatorname{Re}_{\mathrm{B}}^{2} / \mathrm{C}_{\mathrm{dC}} \mathrm{Re}_{\mathrm{C}}^{2}
$$

Thus,

$$
\mathrm{X}_{\mathrm{B}} / \mathrm{X}_{\mathrm{C}} \approx 1.4 \text { for } \mathrm{w} / \mathrm{L}=0.5
$$

To extend these results to other aspect ratios, it was necessary to find the ratio of Best numbers for a different aspect ratio. Podzimek (private communication) determined the drag coefficient of a cylinder with a pyramid on one end, of aspect ratio 
0.166 , and pyramid angle $60^{\circ}$, as

$$
c_{d B}=2.75 \operatorname{Re}^{-0.24}
$$

For a column with equal aspect ratio,

$$
C_{d C}=2.92 R e^{-0.268}
$$

Therefore, the ratio of the Best numbers for equal Reynolds numbers is

$$
\mathrm{X}_{\mathrm{B}} / \mathrm{X}_{\mathrm{C}}=1.06 \text { for } \mathrm{w} / \mathrm{L}=0.166
$$

From these above equations for $\mathrm{X}_{B} / \mathrm{X}_{C}$, the ratio of $\mathrm{X}_{B} / \mathrm{X}_{C}$ can be found in terms of the aspect ratio. It was found that the ratio of $\mathrm{X}_{\mathrm{B}} / \mathrm{X}_{\mathrm{C}}$ in terms of the aspect ratio is

$$
\mathrm{X}_{\mathrm{B}} / \mathrm{X}_{\mathrm{C}} \approx 1.67(\mathrm{w} / \mathrm{L})^{0.25} \text { for } 0.5 \leq \mathrm{w} / \mathrm{L} \leq 0.166 \text {. }
$$

Thus, in calculations of bullet terminal velocities, the Best number for a cylinder with aspect ratio and densities equal to that of a bullet can be used, but multiplied by the ratio of $\mathrm{x}_{\mathrm{B}} / \mathrm{X}_{\mathrm{C}}$. Podzimek found that for the columns with pyramids with an apex angle of $60^{\circ}$, the column moves with a horizontal motion in a direction opposite to that of the apex of the pyramid. Therefore, the falling motion of the bullet is characterizea by a small $\mathrm{Re}_{\mathrm{X}}$. 
b. Aspect ratio

In applying the drag coefficient information given in the previous section to calculations of terminal velocities, information concerning aspect ratios was necessary. Knowing the aspect ratio, combined with the density as a function of length, the Best number can be formulated solely in terms of the length. The aspect ratio of bullet and columnar type crystals was determined using data collected by the author in cirrus clouds. The author analyzed replicas of ice crystals taken during the summers of 1970 and 1971 , and winter of 1972. Crystals were sampled through the sampling tube of the University of Chicago Cloud Physics Laboratory airplane. Although some breakup of crystals did occur, only intact crystals were used to determine the aspect ratio. The c-axis versus a-axis lengths for bullet crystals are shown in Figure 1. Two least squares logarithmic curves were fit through different regions of the data. The equations for width as a function of length are shown in Table I.

In a manner similar to that of bullets, the c-axis to a-axis lengths for columns were determined for crystals collected in cirrus clouds. The results shown in Figure 2 agree quite well with the curve Auer and Veal (1970) fit to their data for columns. The equations fit to the data for columns are shown in Table I.

Also shown in Table I are equations Auer and Veal fit to their data for plates, stellar, plane dendritic, and needle crystals. This information will te used in terminal velocity calculations of these crystal forms. The standard error of estimate for the equations for both bullet and column width is $\pm .032 \mathrm{~mm}$. 


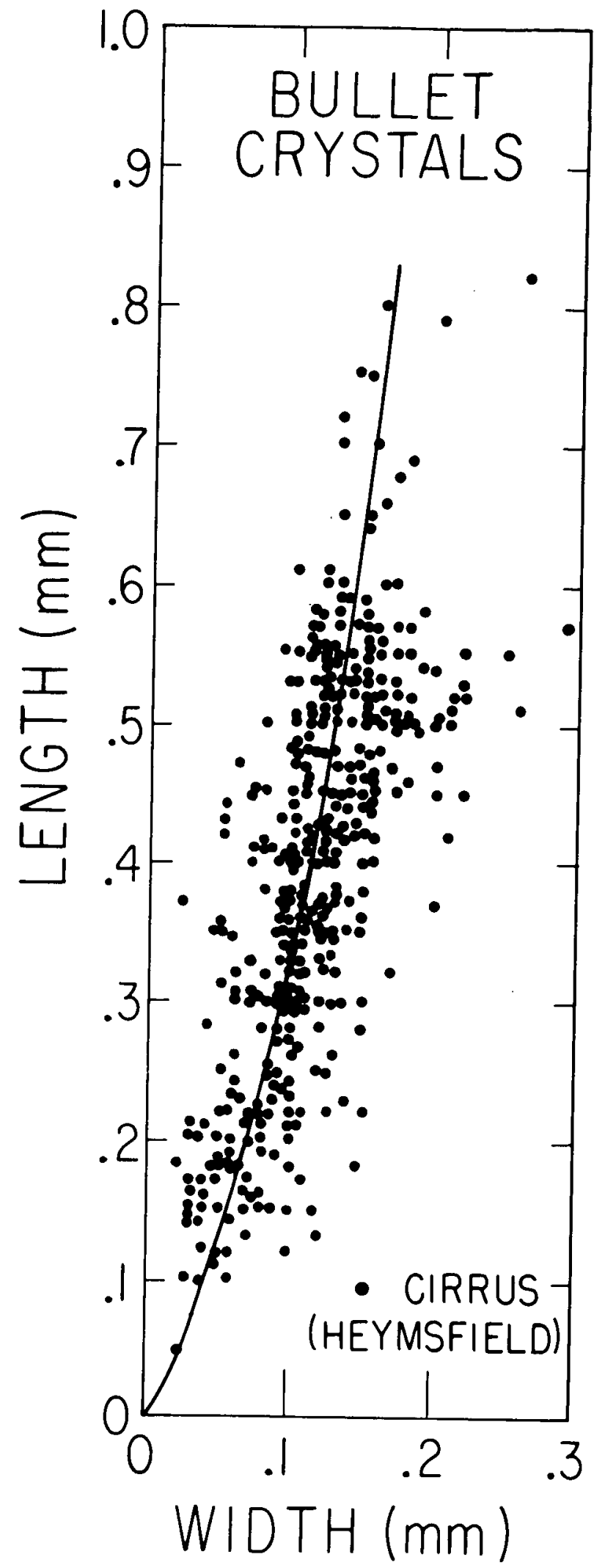

Figure 1. Bullet crystal length versus width from crystals samples in cirrus clouds. 


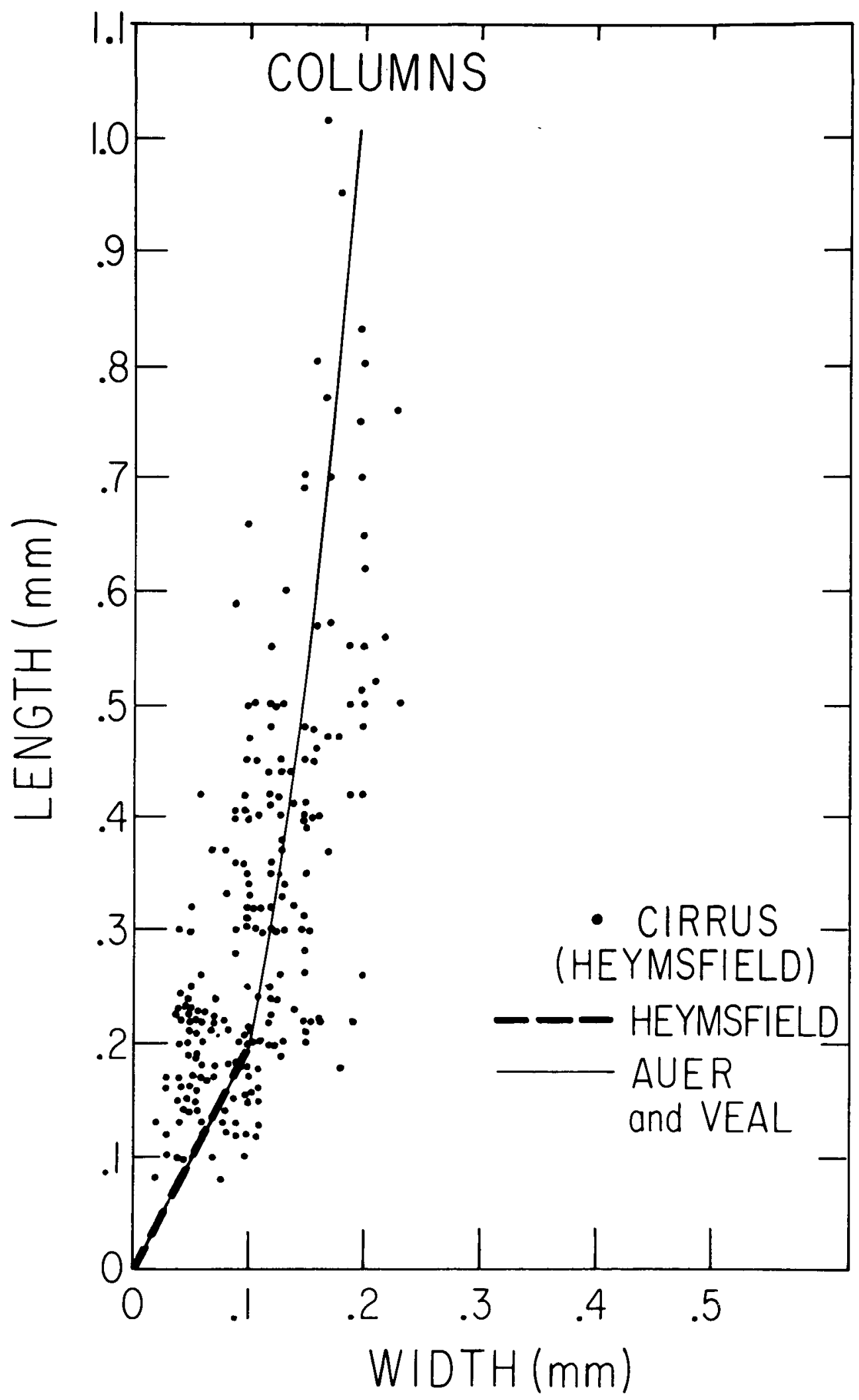

Figure 2. Column crystal length versus width from crystals samples in cirrus clouds.

.$a^{b}$ 


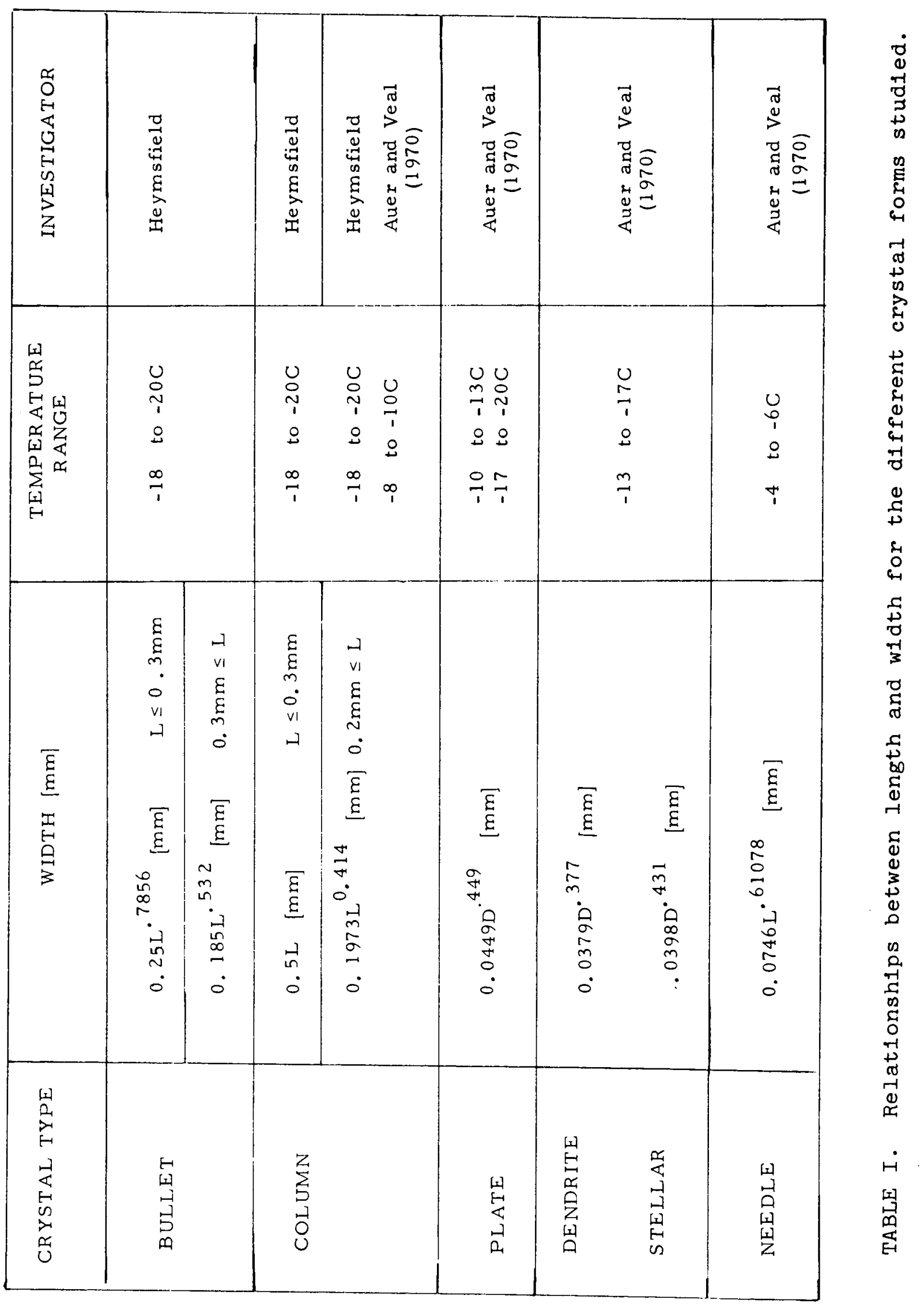

$10 c$ 
c. Ice crystal density

The density of naturally occurring ice crystals shows considerable variation, depending markedly upon the amount of available moisture during growth. In the present study, the density and mass of individual crystals were determined by both estimating the bulk density, and measuring the melted crystal diameter for crystals collected in a cirrostratus, an active cirrostratus (with water droplets present), nimbostratus (with water droplets present), stratocumulus, and at the ground. This provides a complete range of ice crystal densities expected in natural clouds. It was found that the ice crystal density decreases with increasing moisture available for growth. The effect on the terminal velocity of the variation in ice crystal density for the different cloud forms is small. This is discussed in Section 4.

The bulk density, which is defined as the ratio of the crystal mass to the bulk crystal volume, was determined for bullet and columnar crystal forms in a way similar to ono (1969). The crystal mass was determined from the volume of ice in individual crystals, assuming the density of solid ice is $0.9 \mathrm{gm} \mathrm{cm}^{-3}$. The bulk crystal volume is the bulk volume, calculated from c - and a - axis lengths. The crystal replicas used in determining the bulk volume were from cirrostratus, active cirrostratus, and also an icing out altocumulus(with a cloud top at 22,000 feet $(T=-35 \mathrm{C})$ ). Shown in Figure 3 a-c are photographs of typical replicas used in the bulk density computation. The density of bullet and columnar crystals was also determined by collecting crystals within cirrus ( $T \leq-40 \mathrm{C}$ ) in silicone oil, photographing the crystal, and then measuring the melted crystal 

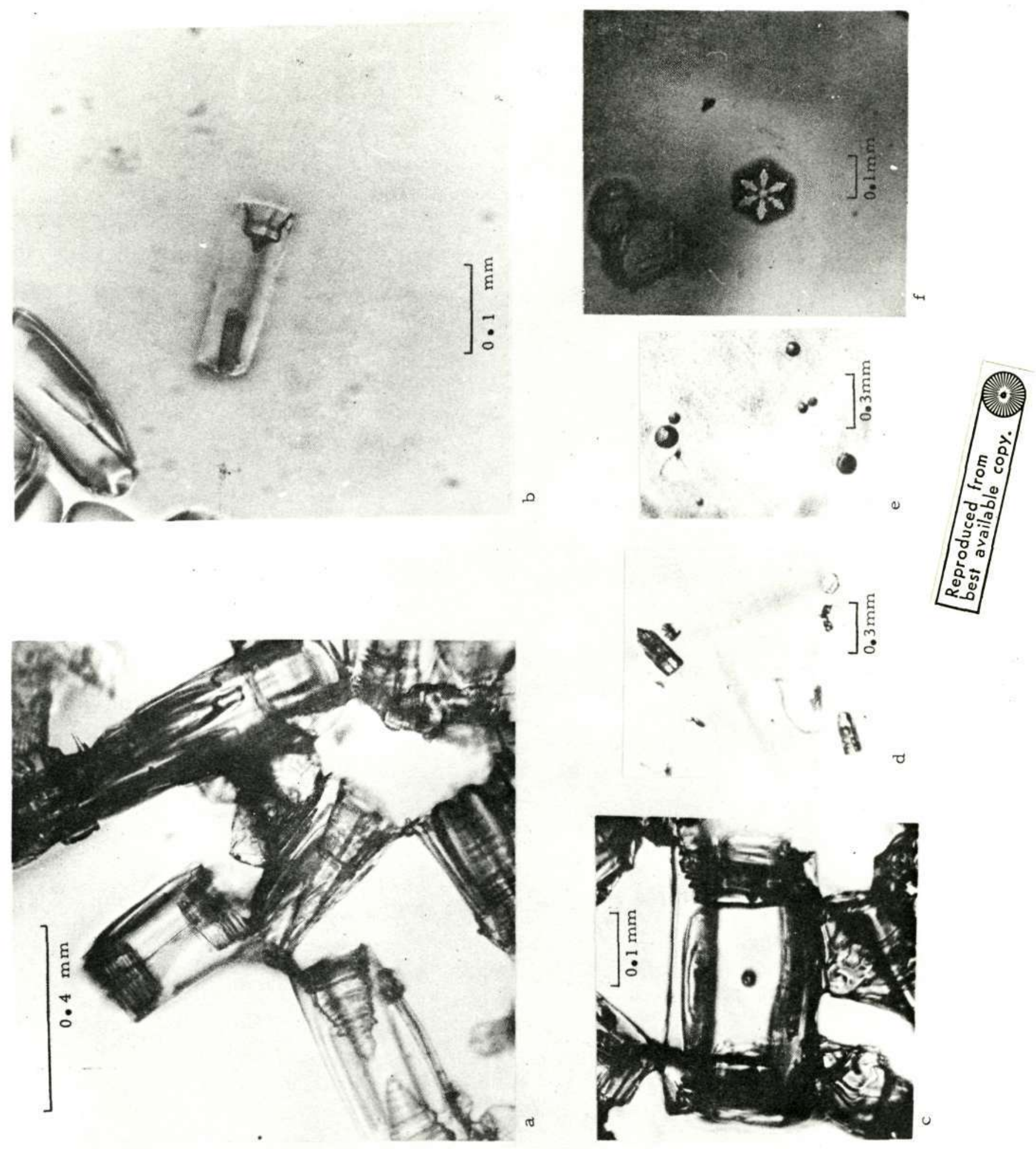

Figure 3. Micro-photographs of particles used for density computation: a) 1cing out altocumulus; b) cirrostratus; c) 1cing out altocumulus; d-e) particles collected (in cirrostratus) and melted in silicone o1l; f) replica in nimbostratus. 
diameter. Typical photography of the unmelted and melted crystals are shown in Figure 3 d-e.

The results for bullet crystals for both the bulk density and measured density shown in Figure 4 show a variation from $0.56 \mathrm{gm} \mathrm{cm}^{-3}$ to $0.9 \mathrm{gm} \mathrm{cm}^{-3}$, but generally a gradual decrease from $0.9 \mathrm{gm} \mathrm{cm} \mathrm{gm}^{-3}$ with increasing length. A least squares equation was fit through the data points to determine the bullet density in terms of the length for the different cloud forms. It was found that for cirrostratus: $P_{s}\left[\mathrm{gm} \mathrm{cm} \mathrm{cm}^{-3}\right]=0.81 \mathrm{~L}^{-.054}$; active cirrostratus: $\rho_{\mathrm{S}}[\mathrm{gm} \mathrm{cm}-3]=0.78 \mathrm{~L}^{-.0038}$; icing out altocumulus: $\rho_{\mathrm{s}}\left[\mathrm{gm} \mathrm{cm} \mathrm{cm}^{-3}\right]=$ $0.65 \mathrm{~L}^{-.097}$. The equation for density used in terninal velocity computation is that for active cirrostratus. This equation is presented in Table II. The results for columnar crystals were similar to those found by ono. The latter included data from Weickmann (1947) for cirrus crystals. The density data shown in Table II for columns was determined by fitting least squares curves through the data provided by ono for both warm region $(-9.5 \leq \mathrm{T} \leq-3.5 \mathrm{C})$ and cold region $(T \leq-22 \mathrm{C})$ columns. The standard error of estimate for the above equations is $\pm 0.06 \mathrm{gm} \mathrm{cm} \mathrm{cm}^{-3}$.

The bulk density of stellar and dendritic crystals was determined by the author from photographs by Nakaya. The crystal density, or actually the crystal cross sectional area compared to that of a hexagonal plate of equal diameter, was taken to be

$$
\rho_{\text {s dendrite }}=\left(A_{\text {crystal }} / A_{\text {total }}\right) 0.9 \mathrm{gm} \mathrm{cm}^{-3} \text {. }
$$

The crystal area Acrystal was measured by a planimeter and the total area $A_{\text {total }}$ was taken to be that of a plate crystal of diameter equal to that of the dendritic crystal. A log least squares 


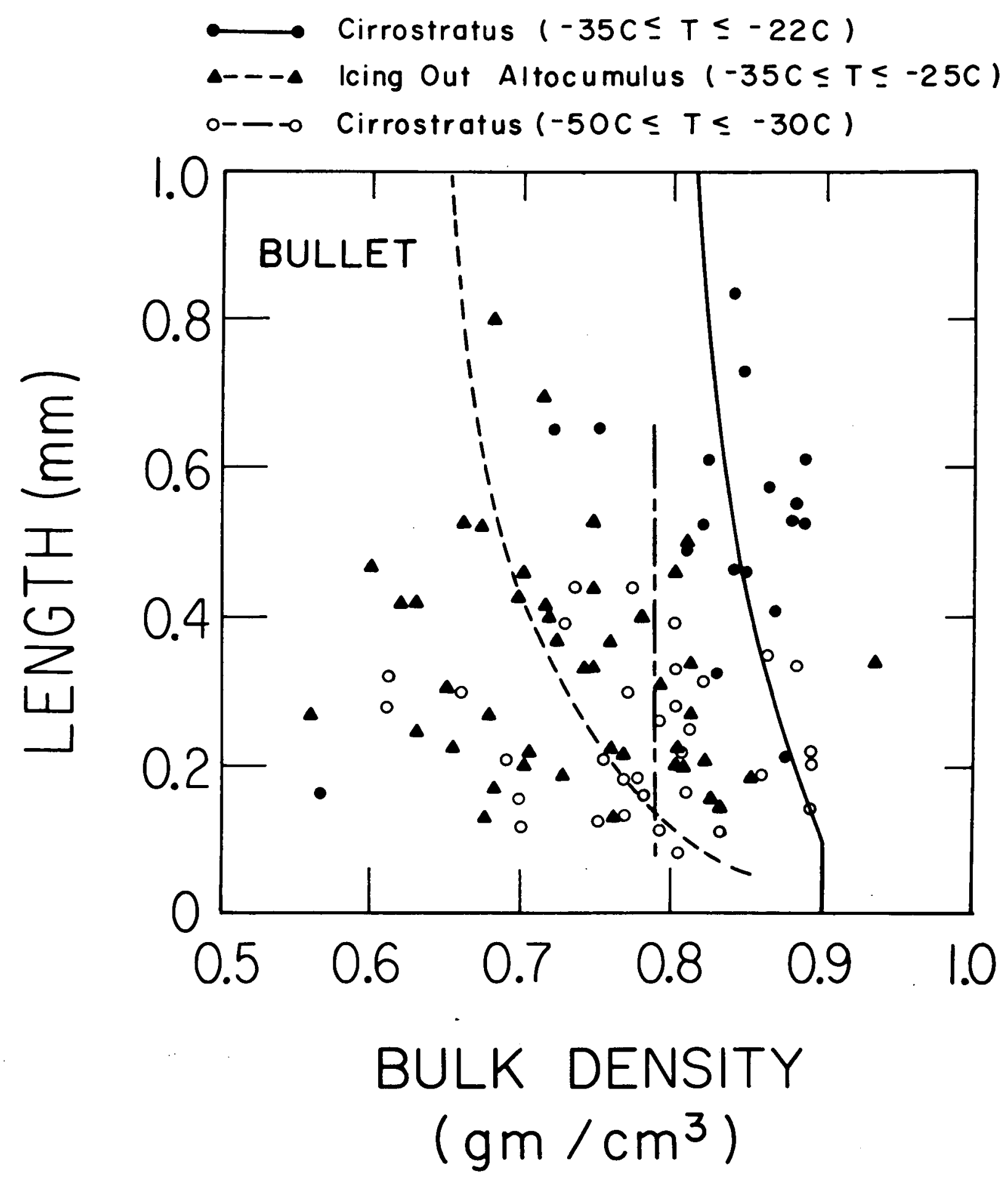

Figure 4. Bullet crystal length versus bulk density for different cloud forms. Also included is density computed from crystal mass. 
curve was fit through the data for stellar with narrow arms, stellar with broad arms and dendrites, and plates with dendritic extensions. The thickness of the crystals was taken to be that for the dendritic forms shown in Table I. The results of density measurements are shown in Figure 4, and equations for these forms are shown in Table II. For lengths smaller than the limits shown in Table II, density is assumed to be $0.9 \mathrm{gm} \mathrm{cm}^{-3}$. The stanuard error of estimate for the above density equations was between $0.05 \mathrm{gm} \mathrm{cm}^{-3}$ and $0.09 \mathrm{gm} \mathrm{cm}^{-3}$. Naturally, there will be a variation in the density and mass of dendrites, depending upon their vapor supply during growth. The mass of numerous dendrites was determined during a snowfall at the ground by photographing the melted crystal in silicone oil. There was up to a $50 \%$ difference in mass from that predicted by the above equations.

The density of plates was found to be approximately 0.9 $\mathrm{gn} \mathrm{cm}^{-3}$. The mass of plates in cirrus clouds was also determined from melting the crystal and very good agreement between the equation for mass for a particular length crystal and measured masses was found. In natural clouds somewhat hollow plates may indeed be found. Shown in Figure $3-f$ is a typical example of such a plate replicated in a nimbostratus at 15500 feet, whose density is computed to be $0.6 \mathrm{gm} \mathrm{cm}^{-3}$. The effect of this density on the calculated terminal velocity is discussed in section 4. In estimating needie density, a least squares logarithmic curve for density as a fuction of length was fit to the data of Ono. For a rimed needle, density was assumed to be $0.9 \mathrm{gm} \mathrm{cm}^{-3}$. The equations for the latter crystal forms appear in Table II. 

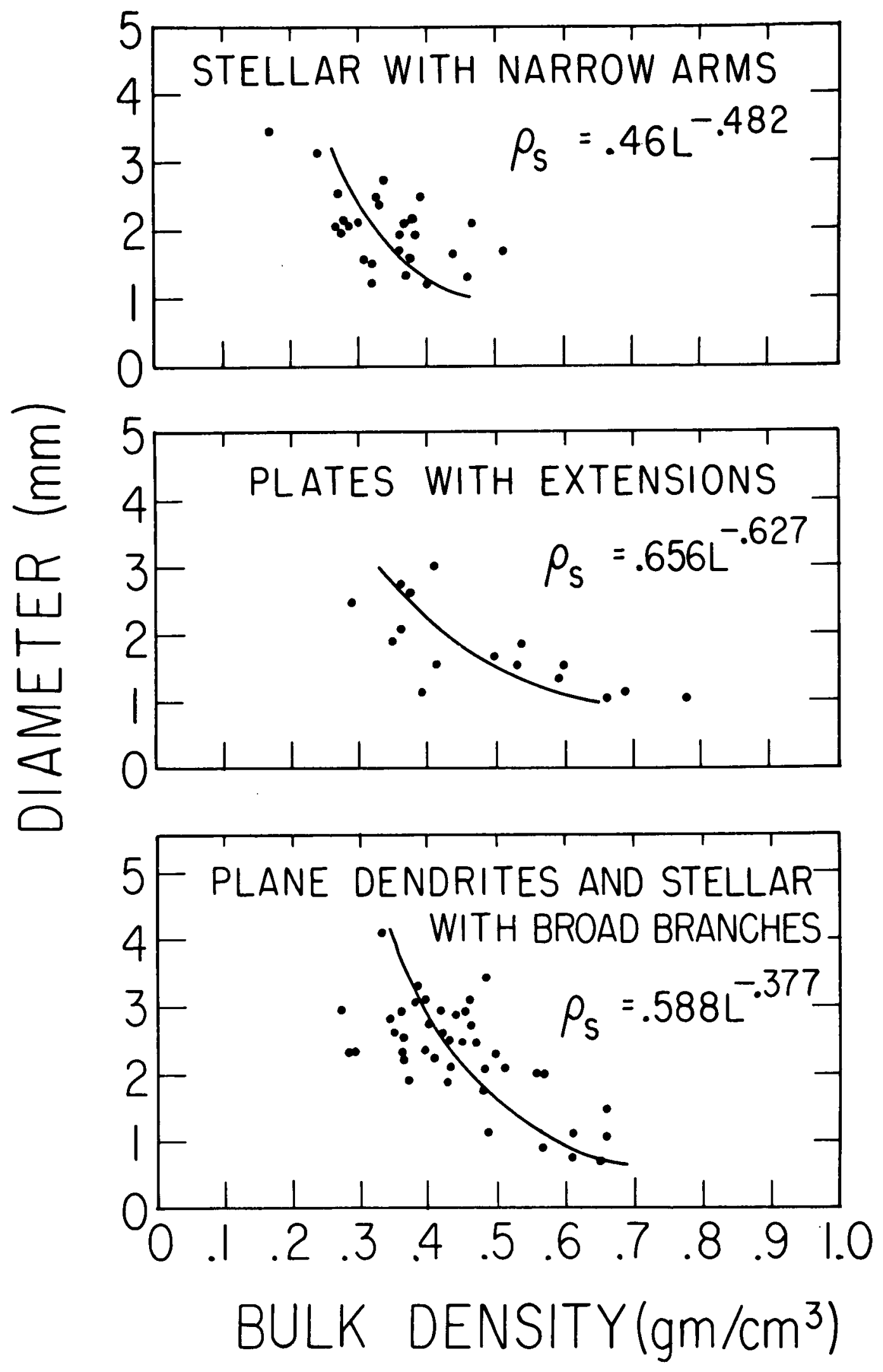

Figure 5. Dendritic diameter versus density.

$13 A$ 


\section{Terminal velocity calculations}

The equations derived for terminal velocities using the information in the previous three subsections are shown in Table II. The results of the terminal velocity calculations are shown in Figure 6 . a. Bullet crystals

Terminal velocities of bullet crystals were calculated assuming the apex angle of the pyramid end to be $60^{\circ}$. This is in agreement with the bulk of our measurements. However, it was observed by the author that the bullet end is often irregular in shape. The results of bullet terminal velocity calculations are shown in Figure 6. a, as well as measurements by Bashkirova and Pershina for $L / w>2$ (aspect ratios less than 0.5 ). The specific altitude at which these measurements are made is not known to the present author. The results are included because they are the only terminal velocity measurements of bullet crystals available. The number $\Delta R e$, shown in Table II, was added to the Reynolds number for bullet crystals, due to the decrease in aspect ratio with increasing crystal length.

b. Columns

The aspect ratio for columns as a function of length shows a departure from 0.5 above $0.2 \mathrm{~mm}$. Therefore, the correction factor $\Delta R e$, described in section $2 a$, was also added to the Reynolds number for columns. This correction factor is shown in Table II. Plotted on Figure $6 \mathrm{~b}$ are terminal velocities measured by Bashkirova and Pershina, as well as calculations from the present study. Again, it is not known at what altitude these measurements are made. However, 


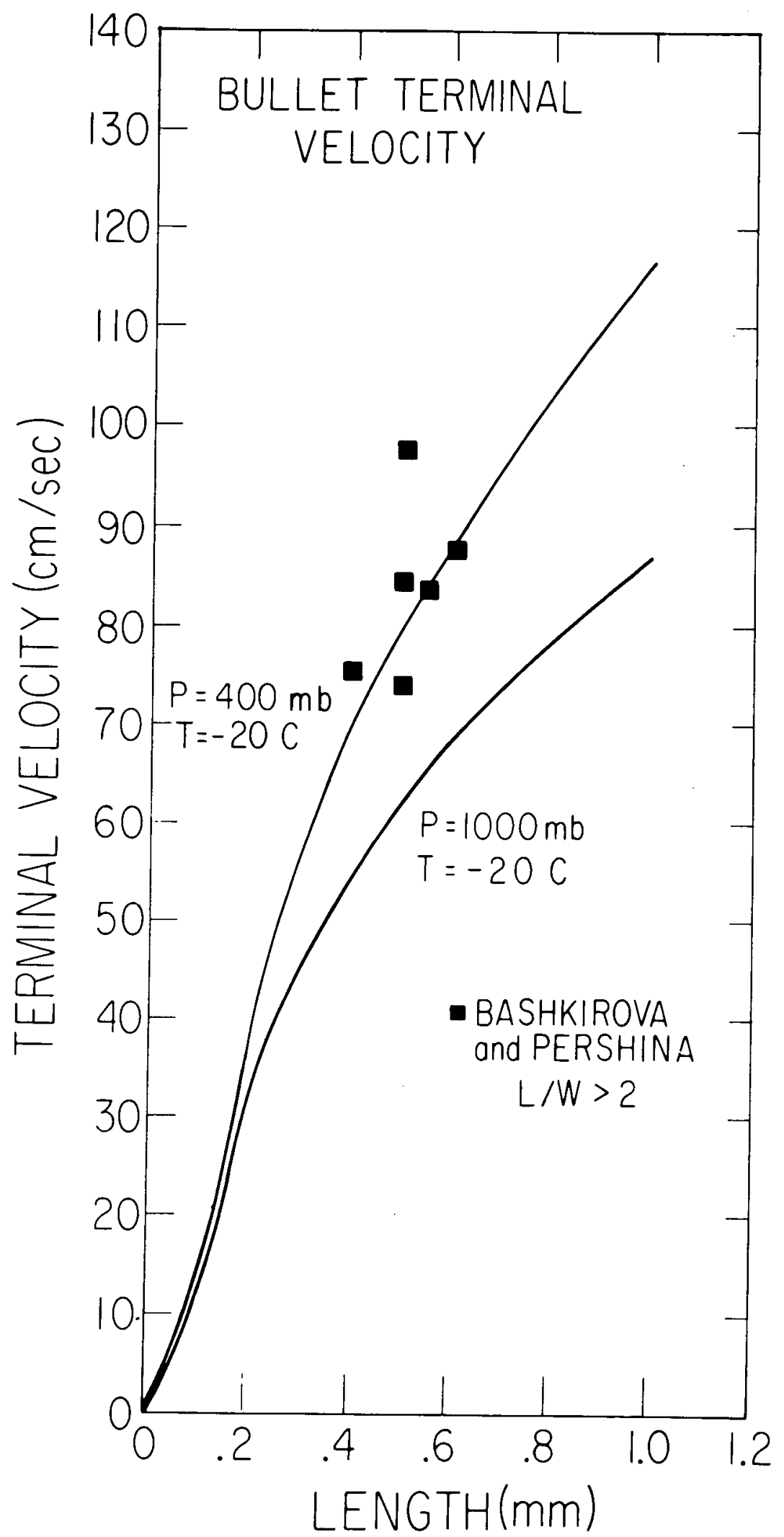

F1gure 6a. Bullet crystal terminal velocity versus length for $1000 \mathrm{mb}$ and $400 \mathrm{mb}$. 


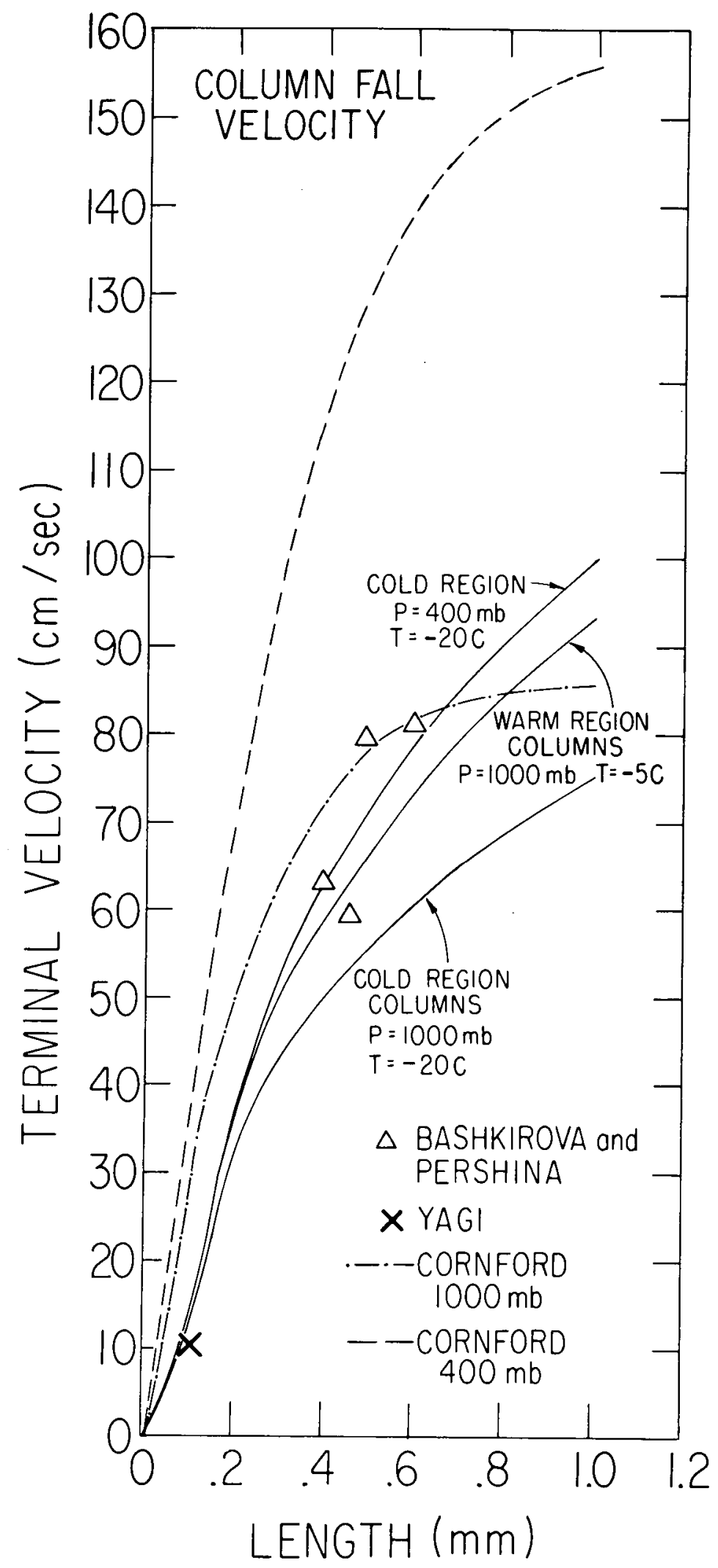

Figure 6b. Column terminal veloc1ty versus length at $1000 \mathrm{mb}$ and $400 \mathrm{mb}$. 
they also represent the only source of data to date. Also plotted is a point by Yagi which represented the mean size and fall speed of a large sample of small crystals of different types. In addition, calculations from equations by Cornford for column fall velocity are shown. There is a $60 \%$ difference between the present values and values using Cornford's equations at $400 \mathrm{mb}$ for a $1 \mathrm{~mm}$ column.

c. Plates

The results of the calculations for plates are shown in Figure $6 \mathrm{c}$. The velocities measured by Bashkirova and Pershina agree quite well with the calculations at $1000 \mathrm{mb}$. Also plotted is the same point determined by Yagi referred to previously. d. Stellar and dendritic crystals

The results of calculations for stellar and dendritic crystals are shown in Figure $6 \mathrm{~d}$, along with measurements of terminal velocities of plane dendrites by Brown, and values by Nakaya and Terada. It is seen that for stellar crystals, the terminal velocity is close to $30 \mathrm{~cm} \mathrm{sec}$, whereas for plane dendrites the terminal velocity is higher. It is felt that the main difference between these calculations and measurements by Brown is that the mass of the crystals in his study was higher than those used in these calculations. This could be due to riming of the crystal, or wider crystal branches. 


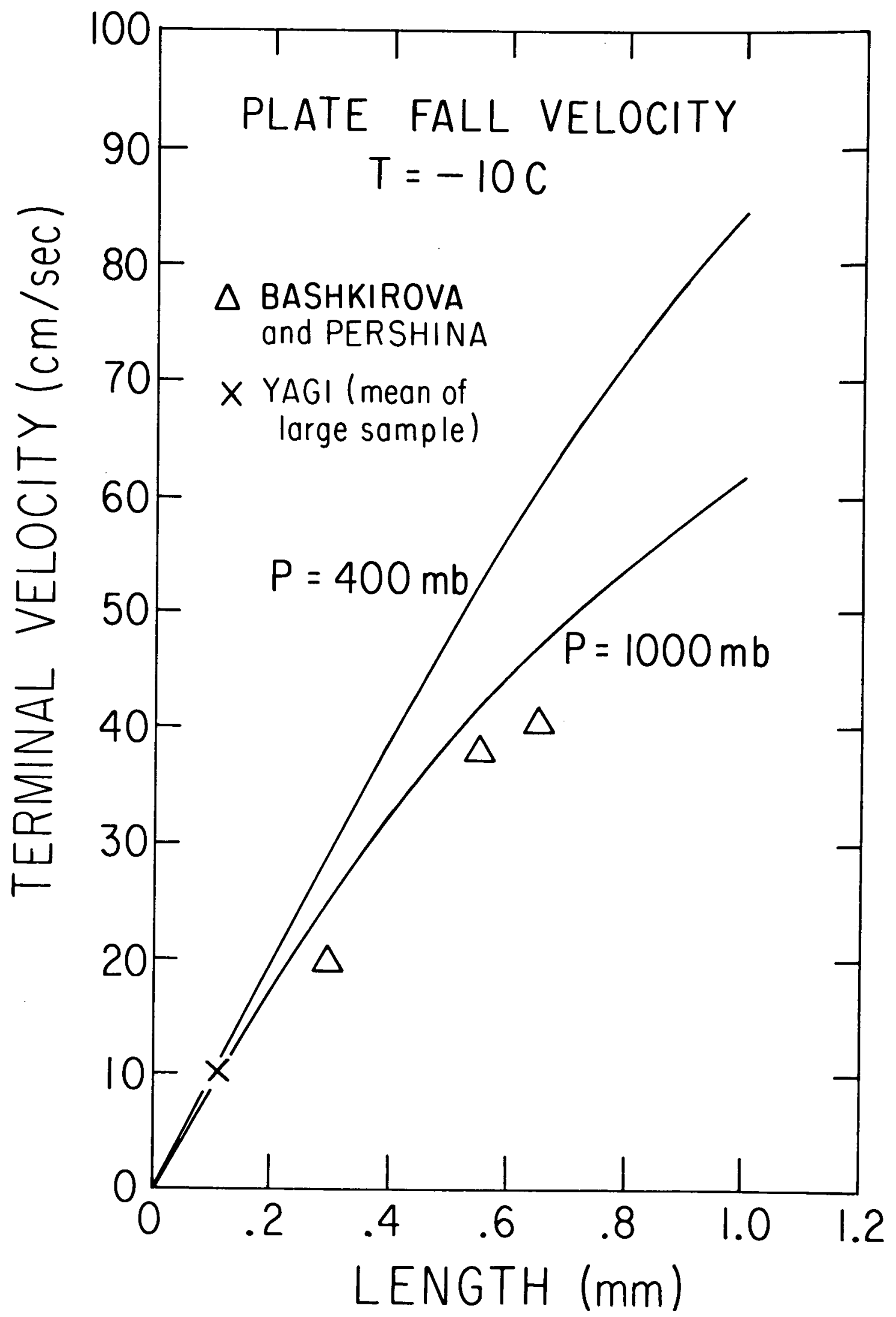

F1gure 6c. Plate terminal veloc1ty versus length at $1000 \mathrm{mb}$ and
$400 \mathrm{mb}$. 150 


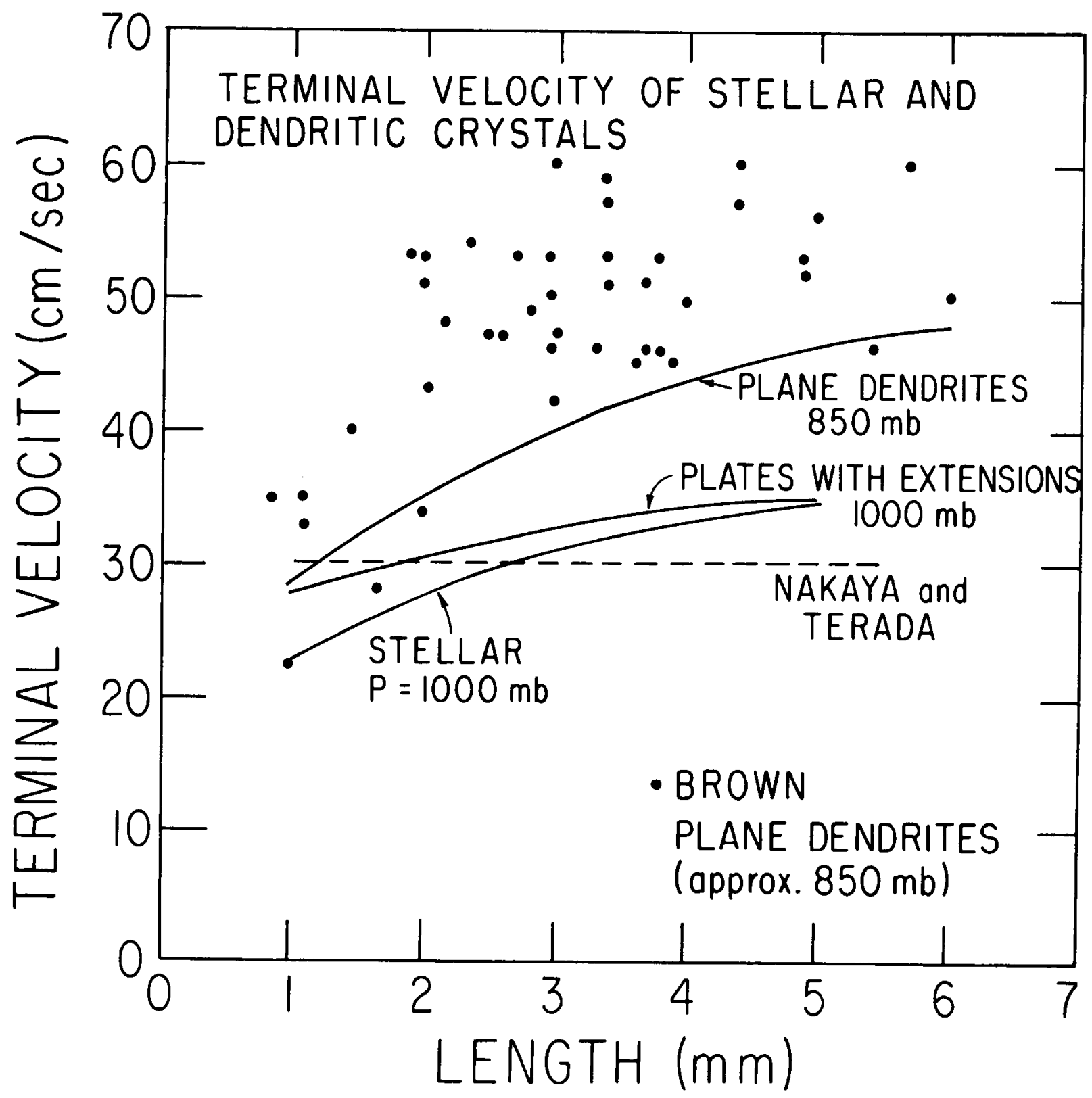

Figure 6d. Terminal velocity versus length for dendrites, plates with extensions, and stellar crystals. 
e. Needles

The needle aspect ratio is very close to 0.1 , which can be deduced from the width-length relationship for needles in Table $I$. Thus, the data by Jayaweera and Cottis for the Reynolds number versus the Best number corresponding to an aspect ratio of 0.1 was used. Calculations of needle terminal velocities are shown in Figure 6 e. The calculations agree quite well with data by Bashkirova and Pershina for both rimed and transparent needles. There was a large difference between terminal velocities for needles in the present study and those of Cornford. For a $5 \mathrm{~mm}$ needle at $400 \mathrm{mb}$, using Cornford's equation for calculating terminal velocity gives a factor of 2 times the terminal velocity found from the present investigation. 


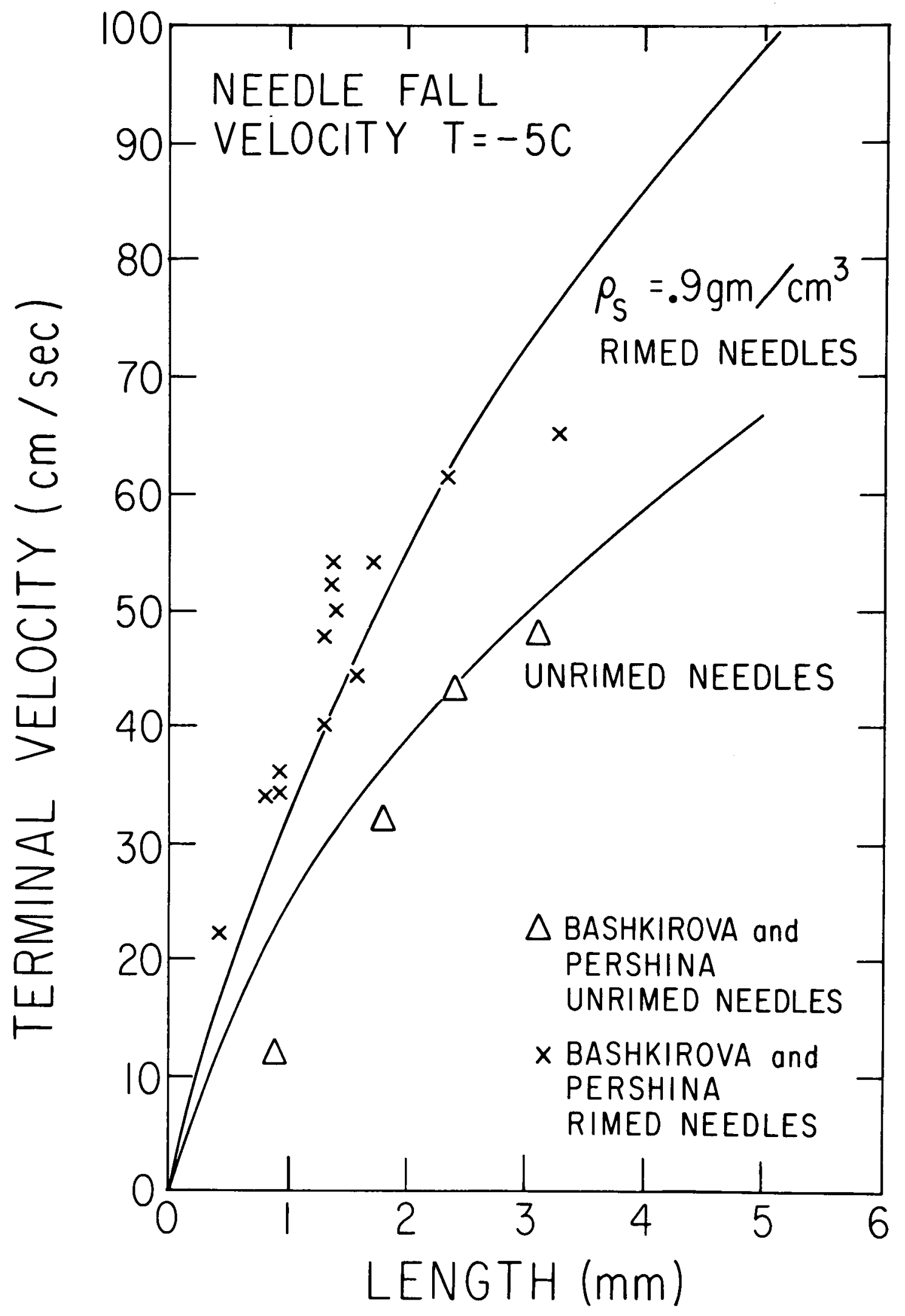
Figure 6e. Calculated terminal velocity versus length for rimed
and unrimed needies. 


\section{f. Specific equations at $1000 \mathrm{mb}$}

Due to the amount of computation involved in obtaining terminal velocities from Table II, it was deemed worthwhle to fit polynomial least squares equations to the terminal velocities calculated from Table II for crystals falling at $1000 \mathrm{mb}$. The equations for ice crystal terminal velocities at $1000 \mathrm{mb}$ are shown in Table III. The maximum error in fitting these least squares equations to the calculations occurs at length $\mathrm{L}=0.1 \mathrm{~mm}$. For bullets, columns, and plates, the error in terminal velocity by these equations compared to the calculations is $20 \%$ for a $0.1 \mathrm{~mm}$ crystal, $5 \%$ for $0.5 \mathrm{~mm}$, and $5 \%$ for $1.0 \mathrm{~mm}$. For needles, the error is $20 \%$ for a $1.0 \mathrm{~mm}$ length crystal and $5 \%$ for a $5 \mathrm{~mm}$ crystal. There is no error for the plane dendritic crystals. The equations for terminal velocities of stellar crystals and plates with extensions are similar to those of plane dendritic crystals. The terminal velocity at $400 \mathrm{mb}$ was estimated by applying the equations for terminal velocities at $1000 \mathrm{mb}$ and since approximately

$$
U_{t} \propto 1 / P^{0.5},
$$

where $\mathrm{P}$ is atmospheric pressure, we have,

$$
\mathrm{U}_{400}=\left(\mathrm{P}_{1000} / \mathrm{P}_{400}\right)^{0.5}\left(\mathrm{U}_{1000}\right) \text {. }
$$

The average error in using this method for determining terminal velocities at $400 \mathrm{mb}$ is approximately $20 \%$ for a $0.5 \mathrm{~mm}$ and $1.0 \mathrm{~mm}$ crystal, independent of crystal habit. These errors are shown in Table III. 


\section{$U$ [CM SEC $\left.^{-1}\right]=F\left[A N T I L O G\left[G+B(\operatorname{LOG} X)+C(\operatorname{LOG} X)^{2}+H(\operatorname{LOG} X)^{3}\right]+\Delta^{\star}\right]$}

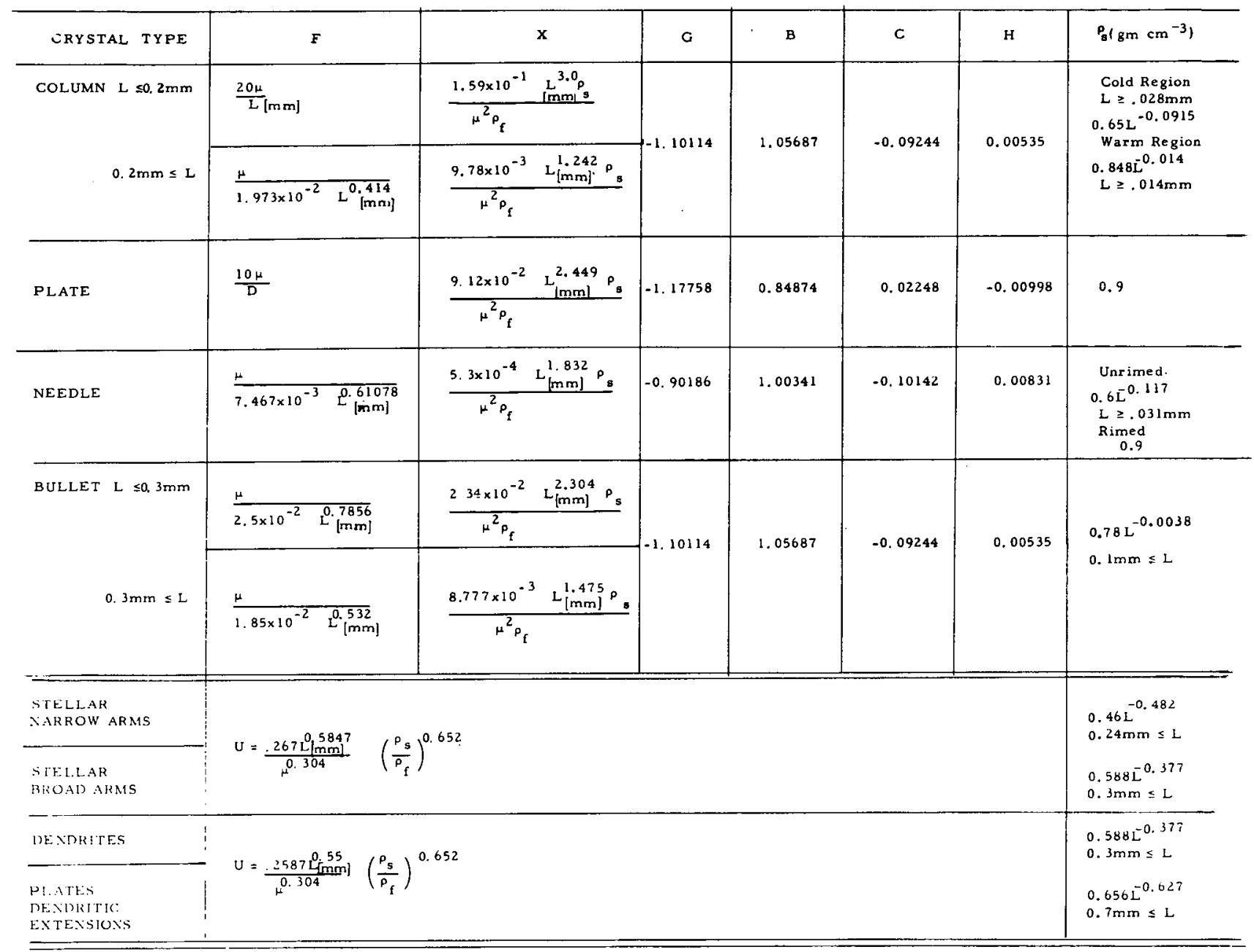

* Only fur COl.umins and BULlets (see text)

$\Delta=\left[\operatorname{antilog}\left(-0.90186+1.0034(\log x)-0.10142(\log x)^{2}+0.0083(\log x)^{3}\right]-\operatorname{antilog}\left[-1.10114+1.05687(\log x)-0.09244(\log x)^{2}+0.00535(\log x)^{3}\right)\right.$ $\left.\left.1-2.56(w / 1) .9)^{5}+1.81\right]\right]$

$\mathrm{L}$ is in $\mathrm{mm}$

$t$ = centigrade temperature

$\mathrm{P}=$ Pressure $(\mathrm{mb})$

$$
\begin{array}{r}
\mu=\frac{4.301 \times 10^{-2}}{\mathrm{P}} \frac{(t+273)^{5 / 2}}{\mathrm{t}+393} \\
\rho_{\mathrm{s}}\left[\mathrm{gm} \mathrm{cm}^{-3}\right] \\
{ }_{f}\left[\mathrm{gm} \mathrm{cm}^{-3}\right]
\end{array}
$$

Columns $\leq 0.2 \mathrm{~mm} \equiv \mathrm{L}$ Bullets $L \leq a 3 \mathrm{~mm}$ $0.3 \mathrm{~mm} \leq \mathrm{L}$

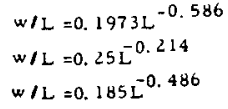

$w / L=0.25 \mathrm{~L}^{-0.214}$

$w / L=0.185 L^{-0.486}$

TABLE II. Equations for terminal velocity as a function of length for the different crystal forms studied. 


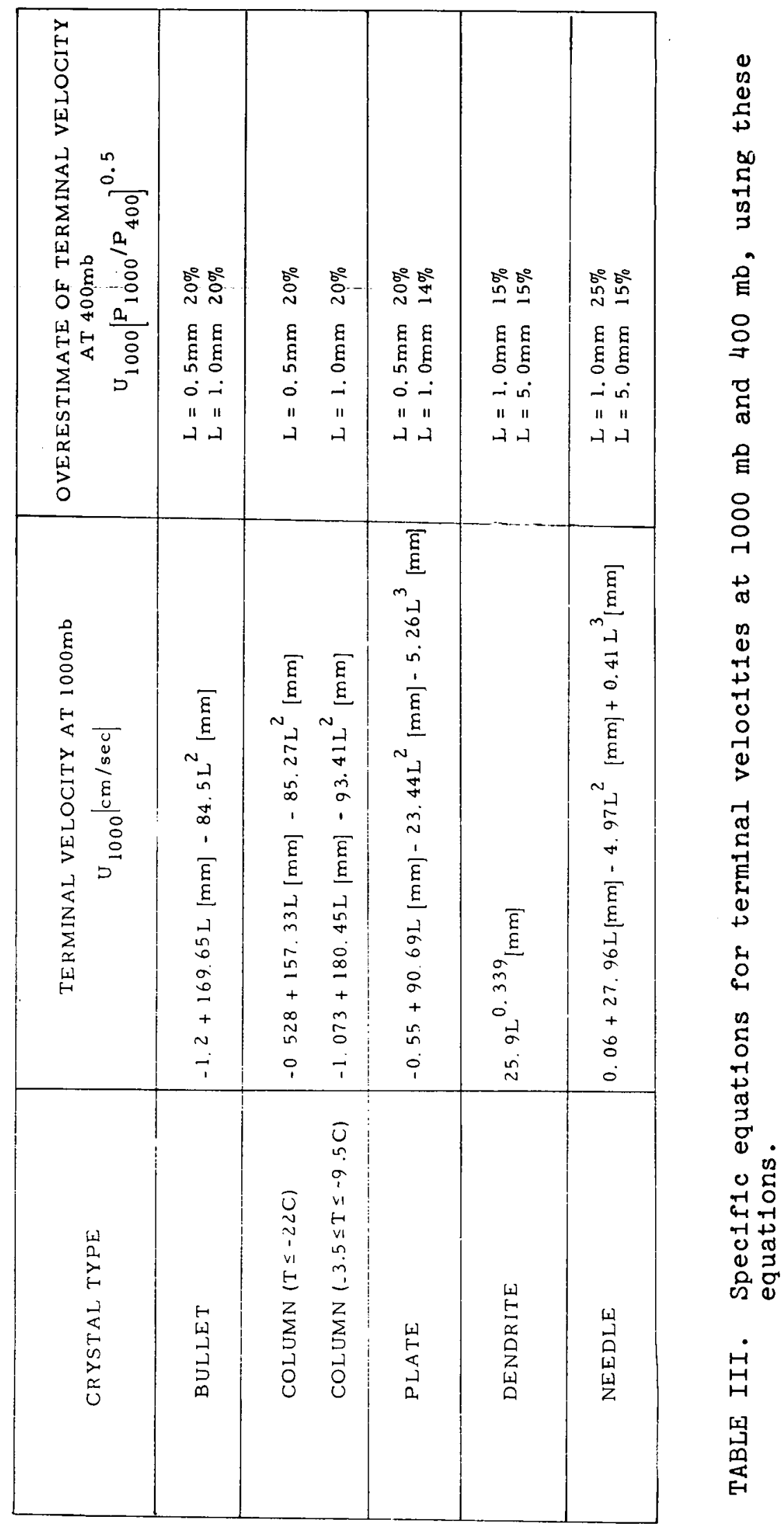


4. Conclusions

Terminal velocities of different ice crystal forms have been calculated using the most recent ice crystal drag coefficients, aspect ratios, and densities. The "general" equations are extremely useful for calculating terminal velocities for the height in the atmosphere at which the crystals are sampled. The "specific" equations for ice crystal terminal velocities at $1000 \mathrm{mb}$ give a good estimate of terminal velocities, and are much simpler to use than the more general equations. The calculations are in good agreement with actual terminal velocity measurements. Calculations from the present study were also compared to calculations from equations which have been derived previousiy and seem to give more reasonable results, especially at higher altitudes.

Calculations show that a $1 \mathrm{~mm}$ bullet crystal will have a greater terminal velocity at $400 \mathrm{mb}$ compared to its velocity at $1000 \mathrm{mb}$ by $35 \%$, a 1 min column by $35 \%$, a I mm plate by $40 \%$, a $1 \mathrm{~mm}$ dendrite by $40 \%$, and a $1 \mathrm{~mm}$ needle by $35 \%$. It was also found that the terminal velocity of the different crystal forms was almost independent of temperature.

To get an indication of the sensitivity of calculated terminal velocities to a lower ice crystal mass, it was found that halving the mass for a crystal at $1000 \mathrm{mb}$ decreases terminal velocity of a $1 \mathrm{~mm}$ bullet crystal by $20 \%$, a $1 \mathrm{~mm}$ column by $23 \%$, a $1 \mathrm{~mm}$ plate by $15 \%$, a $5 \mathrm{~mm}$ needle by $20 \%$, and a $5 \mathrm{~mm}$ dendrite by $35 \%$. Therefore, the terminal velocity is rather insensitive to changes in mass. Further calculations show that the plate crystal with a density estimated to be $0.6 \mathrm{gm} \mathrm{cm}^{-3}$ shown in Figure $3 \mathrm{f}$ would have a $20 \%$ lower terminal velocity than the equations would predict. 
The natural variability in the ice crystal terminal velocity for the same length crystal is largely due to the variability in crystal mass. This variability can be estimated from data presented in the previous sections. By using the values for the standard error of estimate for both width and density for each crystal type, one can calculate the upper and lower limits of the expected terminal velocity. Calculations for bullets and columns show this variability for a $0.5 \mathrm{~mm}$ crystal to be $\pm 15 \%$ at $1000 \mathrm{mb}$ and $\pm 20 \%$ at $400 \mathrm{mb}$, and for a $1.0 \mathrm{~mm}$ crystal to be $\pm 15 \%$ at $1000 \mathrm{mb}$ and $400 \mathrm{mb}$. For plates and dendrites, this variation is less than $\pm 5 \%$.

It can be seen from the above that differences in terminal velocities measured by different researchers for the same crystal habit may largely be due to different altitudes of measurement, and different ice crystal densities and aspect ratios (crystal mass). Therefore, in most terminal velocity measurements, it is also essential to determire the ice crystal density and aspect ratio. 


\section{Acknowledgements}

The author wishes to thank Professor Robert Knollenberg for his helpful review of the manuscript, and Mr. Steve Nelson, for programming the equations. The author also wishes to thank Professor Roscoe R. Braham and the staff of the UnIversity of Chicago Cloud Physics Laboratory.

This research was sponsored by a NASA traineeship, a NASA Grant number NGR-14-001-148, and NSF Grant number GA11088. 


\section{REFERENCES}

Auer, A. and D. Veal, 1970: The dimensions of 1ce crystals in natural clouds. J.Atmos. Sci., 27, 919-926

Bashkorova, G. and T. Pershina, 1964: On the mass of snow crystals and their fall velocities. Trudy G. G. 0., \#165, 83-100

Brown, S., 1970: The terminal velocities of ice crystals. Proceedings of the International Conference on Cloud Physics, Fort Collins, Colorado, $47-48$

Cornford, S. 1965: Fall speeds of precipitation elements. Quart. J. Roy. Meteor. Soc., 91,91-94

Jayaweera, K. O. K. F., and R. E. Cottis, 1969: Fall velocities of platelike and columnar ice crystals. Quart. J. Roy. Meteor. Soc., 95, 703-709

Magono, C., 1954: On the falling velocity of solid precipitation elements. Sci. Rep., Yokohama Nat. Univ. Sec., 1, (3), $33-40$

Nakaya, U., 1954: Snow Crystals. Harvard University Press, Cambridge, 510.

Nakaya, V., and T. Terada, 1935: Simultaneous observations of the mass, falling velocity and form of individual snow crystals. J. Fac. Sci. Hokkaido Imp. Univ., 1, Series 2, $191-201$.

Ono, A., 1969: The shape and riming properties of ice crystals in natural clouds. J.Atmos. Sci. 26, 138-147. Podzimek, J., 1968: Aerodynamic conditions of ice crystal aggregation. Proceedings of the International Conference on Cloud Physics, Toronto, 295-299 


\section{REFERENCES}

Schmiedel, J., 1928: Experimental investigation of the drag coefficlents of spheres and disks over a wide range of Reynolds numbers, Phy. Z., 29, 593-610.

Willmarth, W. W., N.E. Hawk, and R.L. Harvey, 1964: Steady \& unsteady motion and wakes of freely falling disks. The Physics of Fluids, 7, 107-208

Welckmann, H., 1947: Die Eisphase in der Atmophere. Translation by Mr. M. G. Sutton., Lib. Trans. 273, Royal Alrcraft Establishment, Farmborough, 96pp.

Yag1, T. 1970: Measurement of the fall veloc1ty of ice crystals drifting in supercooled fog. J. Meteor. Soc., Japan, 48, $287-292$. 